\title{
MODELLING AND OPTIMIZATION OF GAS METAL ARC WELDING USING RESPONSE SURFACE METHODOLOGY
}

\begin{tabular}{|c|c|}
\hline $\begin{array}{c}\text { Amit Kumar } \\
\text { Mechanical engineering department } \\
\text { Motilal Nehru National Institute of Technology, } \\
\text { Allahabad, India } \\
\text { akyadav.me@gmail.com }\end{array}$ & $\begin{array}{c}\text { Pradeep K Yadav, M. K. Khurana } \\
\text { Mechanical engineering department } \\
\text { Motilal Nehru National Institute of Technology, } \\
\text { Allahabad, India }\end{array}$ \\
khuranamnnit@gmail.com \\
\hline
\end{tabular}

\begin{abstract}
GMAW is a complicated process with many interrelated parameters affecting the quality of the welded joint. The process variables with the maximum influence are the welding current, welding voltage, travel speed and arc efficiency. Response surface methodology was used to predict the weld penetration of gas metal arc welded mild steel. The experiments were conducted based on three factors, three-level, and central composite face centered design with full replications technique, and mathematical model was developed. The results obtained through response surface methodology were verified through a confirmation experiment.

The welding parameters such as speed, welding current and voltage have been optimized for material AISI 1020 using GMAW process. To fortify the robustness of experimental design, a confirmation test was performed at selected optimal process parameter setting. Observations from this method may be useful for automotive sub-assemblies, shipbuilding and vessel fabricators and operators to obtain optimal welding conditions.
\end{abstract}

Keywords - Gas metal arc welding, penetration, response surface methodology,central composite design.

\section{INTRODUCTION}

The GMAW has got wide applications in industries due to the advantages such as high reliability, all position capability, low cost, high productivity, high deposition rate, ease of use, absence of fluxes and cleanliness [1]. This process establishes an electric arc between a continuous filler metal electrode and the weld pool. Gases are used for shielding which flow through the nozzle of the welding torch. The most important gases which have been used in order to shield the weld pool are $\operatorname{Argon}(\mathrm{Ar})$, Helium (He) and $\mathrm{CO}_{2}$ and their mixtures.

GMAW is a complicated process with many interrelated parameters affecting the quality of the welded joint. The process variables with the maximum influence are the welding current, welding voltage, travel speed and arc efficiency [2].

The important factors for weld bead geometry are bead width, bead height and weld penetration.

Usually the parameters of welding are determined purely on the basis of experience of the operator or from the hand book. However, these selected welding process parameters does not ensure the optimum weld bead geometry.

To obtain the desired penetration, it is essential to have a complete control over the relevant process parameters to maximize the penetration on which the quality of a weld is based. Therefore, it is very important to select and control the welding process parameter for obtaining the maximum penetration. Various prediction methods can be applied to define the desired output variables through developing mathematical models to specify the relationship between the input parameters and output variables. The response surface methodology (RSM) is helpful in developing a suitable approximation for the true functional relationship between the independent variables and the response variable that may characterize the nature of the joints [3].

It has been proved by several researchers [4-7] that efficient use of statistical design of experimental techniques, allows development of an empirical methodology, to incorporate a scientific approach in the fusion welding procedure. Recently, in the fields of materials joining, computer aided artificial neural network (ANN) modeling has gained increased importance. DUTTA et al [8] modeled the gas tungsten arc welding process using conventional regression analysis and neural network-based approaches and found that the performance of ANN was better compared with regression analysis. ATES et al [9] presented the use of artificial neural network for prediction of gas metal arc welding parameters. OKUYUCU et al [10] showed the possibility of the use of neural networks for the calculation of the mechanical properties of friction stir welded (FSW) aluminium plates incorporating process parameters such as rotational speed and welding speed.

Even though sufficient literature is available on Gas metal arc welding of mild steel, no systematic study has been reported so far to correlate the process parameters and penetration of welded mild steel joints. Hence, in this investigation, the design was used to conduct the experiments for exploring the interdependence of the process parameters and second order quadratic model for the prediction of weld penetration was developed from the data obtained by conducting the experiments. The results obtained through response surface methodology were validated by performing a confirmation test.

\section{A. Experimental Details}

The experiments were carried out with the help of INVA MIG 400 welding machine along with $\mathrm{CO}_{2}$ as shielding gas. These experiments are based on central composite design of response surface methodology. All the experiments were conducted on mild steel specimens having $200 \times 50 \times 6 \mathrm{~mm}$ size as a base metal and ER 70 S-6 wire electrode having $0.8 \mathrm{~mm}$ diameter as filler wire. The chemical composition of base metal by weight $\%$ is given in table I.

TABLE I. The chemical composition of the base metal weight $\%$

\begin{tabular}{|c|c|c|c|c|c|c|}
\hline & $\mathrm{C}$ & $\mathrm{Mn}$ & $\mathrm{Si}$ & $\mathrm{S}$ & $\mathrm{P}$ & $\mathrm{Ni}$ \\
\hline Base metal & 0.12 & 0.9 & 0.013 & 0.008 & 0.013 & .004 \\
\hline
\end{tabular}




\section{Asia Pacific Journals}

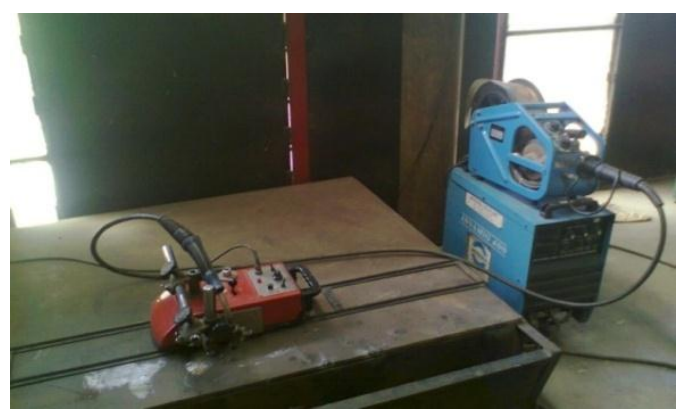

Figure 2: Experimental Setup

In this study, three input parameters namely welding current, arc voltage and welding speed have been chosen on the basis of trial and error testing. For the selection of parameters about 40 experiments were done. Several different combinations of welding speed, current and voltage were taken. Voltage ranges from, $22 \mathrm{~V}-26 \mathrm{~V}$, Welding speed ranges from $40 \mathrm{~cm} / \mathrm{min}-80$ $\mathrm{cm} / \mathrm{min}$ and current ranges from $95 \mathrm{~A}-115 \mathrm{~A}$.

Experiments have been done with the welding process parameters given in table II, to obtain closed square butt welding on mild steel $6 \mathrm{~mm}$ thickness with $50 \mathrm{~mm} \times 200 \mathrm{~mm}$ dimensions by gas metal arc welding process.

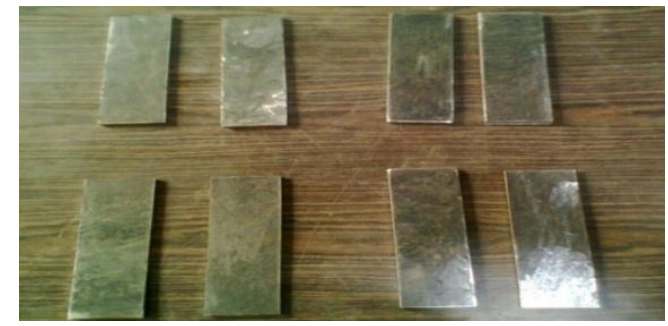

Figure 3: Mild steel specimens before welding

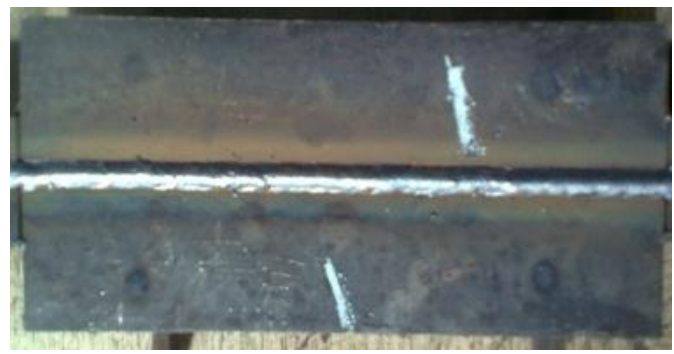

Figure 4: Mild steel specimens after welding

TABLE II. Welding variable and their levels

\begin{tabular}{|c|c|c|c|c|}
\hline Parameter & Unit & $\begin{array}{c}\text { Level (- } \\
1)\end{array}$ & $\begin{array}{c}\text { Level } \\
(0)\end{array}$ & $\begin{array}{c}\text { Level } \\
(+1)\end{array}$ \\
\hline $\begin{array}{c}\text { Voltage } \\
(\mathrm{V})\end{array}$ & Volt(V) & 22 & 24 & 26 \\
\hline Current(C) & Ampere(A) & 95 & 105 & 115 \\
\hline $\begin{array}{c}\text { Welding } \\
\text { Speed(Ws) }\end{array}$ & $\mathrm{cm} / \mathrm{min}$ & 40 & 60 & 80 \\
\hline
\end{tabular}

\section{B. Development of mathematical model}

\subsection{Response surface methodology}

Response surface methodology (RSM) is a collection of mathematical and statistical technique useful for analyzing problems in which several independent variables influence a dependent variable or response and the goal is to optimize the response [11]. In many experimental conditions, it is possible to represent independent factors in quantitative form as given in Eq.(1). Then these factors can be thought of as having a functional relationship or response as follows:

$$
\mathrm{Y}=\Phi\left(\mathrm{x}_{1}, \mathrm{x}_{2}, \ldots \mathrm{x}_{\mathrm{k}}\right) \pm \mathrm{e}_{\mathrm{r}}
$$

Between the response $\mathrm{Y}$ and $\mathrm{x} 1, \mathrm{x} 2, \ldots, \mathrm{xk}$ of $\mathrm{k}$ quantitative factors, the function $\Phi$ is called response surface or response function. The residual $\mathrm{e}_{\mathrm{r}}$ measures the experimental errors. For a given set of independent variables, a characteristic surface is responded. When the mathematical form of $\Phi$ is not known, it can be approximate satisfactorily within the experimental region by polynomial. In the present investigation, RSM has been applied for developing the mathematical model in the form of multiple regression equations for the quality characteristic of the gas metal arc welded mild steel. In applying the response surface methodology, the independent variable was viewed as a surface to which a mathematical model is fitted. The second order polynomial (regression) equation used to represent the response surface $\mathrm{Y}$ is given by [12]

$$
Y=b 0+\Sigma b i x i+\Sigma b i i x i+\Sigma b i j x i x j+e
$$

and for three factors, the selected polynomial could be expressed as:

$$
\begin{gathered}
\sigma=b 0+b 1(N)+b 2(S)+b 3(F)+b 11(N 2)+b 22(S 2)+b 33(F 2)+ \\
b 12(N S)+b 13(N F)+b 23(S F)
\end{gathered}
$$

In order to estimate the regression coefficients, a number of experimental design techniques are available. In this work, central composite face centered design (Table 4) was used which fits the second order response surfaces very accurately.

Central composite face centered (CCF) design matrix with the star points being at the center of each face of factorial space was used, so $\alpha= \pm 1$. This variety requires three levels of each factor. CCF designs provide relatively high quality predictions over the entire design space and do not require using points outside the original factor range. The upper limit of a factor was coded as +1 , and the lower limit was coded as -1 . All the coefficients were obtained applying central composite face centered design using the MINITAB 17 statistical software package. 
Asia Pacific Journals

Table 4. Experimental design matrix and results

\begin{tabular}{|c|c|c|c|c|c|c|c|r|}
\hline S.No. & Run & $\mathrm{C}$ & $\mathrm{V}$ & $\mathrm{Ws}$ & $\mathrm{C}$ & $\mathrm{V}$ & $\mathrm{Ws}$ & Penetration \\
\hline 1 & 1 & -1 & -1 & -1 & 95 & 22 & 40 & 2.46 \\
\hline 2 & 2 & 1 & 1 & -1 & 115 & 26 & 40 & 3.19 \\
\hline 3 & 3 & 1 & -1 & 1 & 115 & 22 & 80 & 2.94 \\
\hline 4 & 4 & -1 & 1 & 1 & 95 & 26 & 80 & 2.59 \\
\hline 5 & 5 & 0 & 0 & 0 & 105 & 24 & 60 & 2.97 \\
\hline 6 & 6 & 0 & 0 & 0 & 105 & 24 & 60 & 2.99 \\
\hline 7 & 7 & 1 & -1 & -1 & 115 & 22 & 40 & 3.02 \\
\hline 8 & 8 & -1 & 1 & -1 & 95 & 26 & 40 & 2.64 \\
\hline 9 & 9 & -1 & -1 & 1 & 95 & 22 & 80 & 2.36 \\
\hline 10 & 10 & 1 & 1 & 1 & 115 & 26 & 80 & 3.16 \\
\hline 11 & 11 & 0 & 0 & 0 & 105 & 24 & 60 & 2.97 \\
\hline 12 & 12 & 0 & 0 & 0 & 105 & 24 & 60 & 2.95 \\
\hline 13 & 13 & -1 & 0 & 0 & 95 & 24 & 60 & 2.67 \\
\hline 14 & 14 & 1 & 0 & 0 & 115 & 24 & 60 & 3.14 \\
\hline 15 & 15 & 0 & -1 & 0 & 105 & 22 & 60 & 2.92 \\
\hline 16 & 16 & 0 & 1 & 0 & 105 & 26 & 60 & 3.01 \\
\hline 17 & 17 & 0 & 0 & -1 & 105 & 24 & 40 & 2.89 \\
\hline 18 & 18 & 0 & 0 & 1 & 105 & 24 & 80 & 2.84 \\
\hline 19 & 19 & 0 & 0 & 0 & 105 & 24 & 60 & 2.96 \\
\hline 20 & 20 & 0 & 0 & 0 & 105 & 24 & 60 & 2.98 \\
\hline
\end{tabular}

\subsection{Checking adequacy of model}

The adequacy of the developed model was tested using the analysis of variance (ANOVA) technique and the results of second order response surface model fitting in the form of analysis of variance (ANOVA) are given in Table 5.

Table 5. ANOVA result for penetration

\begin{tabular}{|c|c|c|c|c|c|}
\hline Source & DOF & Adj SS & Adj MS & $\begin{array}{c}\text { F- } \\
\text { Value }\end{array}$ & P-Value \\
\hline Model & 11 & 0.958168 & 0.087106 & 74.08 & 0.000 \\
\hline Blocks & 2 & 0.000133 & 0.000067 & 0.06 & 0.945 \\
\hline Linear & 3 & 0.834110 & 0.278037 & 236.46 & 0.000 \\
\hline $\mathrm{C}$ & 1 & 0.745290 & 0.745290 & 633.84 & 0.000 \\
\hline $\mathrm{V}$ & 1 & 0.079210 & 0.079210 & 67.36 & 0.000 \\
\hline Ws & 1 & 0.009610 & 0.009610 & 8.17 & 0.021 \\
\hline Square & 3 & 0.096904 & 0.032301 & 27.47 & 0.000 \\
\hline $\mathrm{C}^{*} \mathrm{C}$ & 1 & 0.011341 & 0.011341 & 9.64 & 0.015 \\
\hline $\mathrm{V} * \mathrm{~V}$ & 1 & 0.000067 & 0.000067 & 0.06 & 0.817 \\
\hline Ws*Ws & 1 & 0.029593 & 0.029593 & 25.17 & 0.001 \\
\hline $\begin{array}{c}\text { 2-Way } \\
\text { Interaction }\end{array}$ & 3 & 0.001500 & 0.000500 & 0.43 & 0.740 \\
\hline $\mathrm{C} * \mathrm{~V}$ & 1 & 0.000050 & 0.000050 & 0.04 & 0.842 \\
\hline $\mathrm{C} * \mathrm{Ws}$ & 1 & 0.000200 & 0.000200 & 0.17 & 0.691 \\
\hline $\mathrm{V} * \mathrm{Ws}$ & 1 & 0.001250 & 0.001250 & 1.06 & 0.333 \\
\hline Error & 8 & 0.009407 & 0.001176 & & \\
\hline Lack-of-Fit & 5 & 0.008807 & 0.001761 & 8.81 & 0.052 \\
\hline Pure Error & 3 & 0.000600 & 0.000200 & & \\
\hline Total & 19 & 0.967575 & & & \\
\hline \multirow{3}{*}{\multicolumn{2}{|c|}{$\begin{array}{c}\text { R-Squared } \\
\text { Adjusted R-Squared } \\
\text { Predicted R-Squared }\end{array}$}} & 0.99 & & & \\
\hline & & 0.97 & & & \\
\hline & & 0.83 & & & \\
\hline
\end{tabular}

After determining the significant coefficients (at 95\% confidence level), the final model was developed using only these coefficients and the final mathematical model to estimate weld penetration is given as:

Penetration $(\mathrm{mm})=2.97+0.273(\mathrm{C})+0.089(\mathrm{~V})-0.031(\mathrm{Ws})-$ $0.0025(\mathrm{CV})+0.005(\mathrm{CWs})+0.125(\mathrm{VWs})-0.065(\mathrm{C})^{2}$

$-0.105(\mathrm{Ws})^{2}-0.005(\mathrm{Ws})$
The determination coefficient $\left(\mathrm{R}^{2}\right)$ indicates the goodness of fit for the model. In this case, the value of the determination coefficient $\left(\mathrm{R}^{2}=0.99\right)$ indicates that only less than $1 \%$ of the total variations are not explained by the model. The value of adjusted determination coefficient (adjusted $\mathrm{R}^{2}=0.97$ ) is also high, which indicates a high significance of the model.

Predicted $\mathrm{R}^{2}$ is also in a good agreement with the adjusted $\mathrm{R}^{2}$. Adequate precision compares the range of predicted values at the design points to the average prediction error. At the same time a relatively lower value of the coefficient of variation indicates improved precision and reliability of the conducted experiments.

The value of probability $>\mathrm{F}$ in Table 5 for model is less than 0.05 , which indicates that the model is significant. In the same way, welding current, arc voltage (V) and welding speed(S), second order term of welding current and welding speed are significant. Interaction effect of welding current with arc voltage $(\mathrm{AV})$, interaction effect of welding current with welding speed (AS), interaction effect of arc voltage with welding speed (VS) and second order term of arc voltage (V) have insignificant effect. Lack of fit is non significant as it is desired. The normal probability plot of the residuals for penetration shown in Fig.4 reveals that the residuals are falling on the straight line, which means the errors are distributed normally [13]. All the above consideration indicates an excellent adequacy of the regression model.

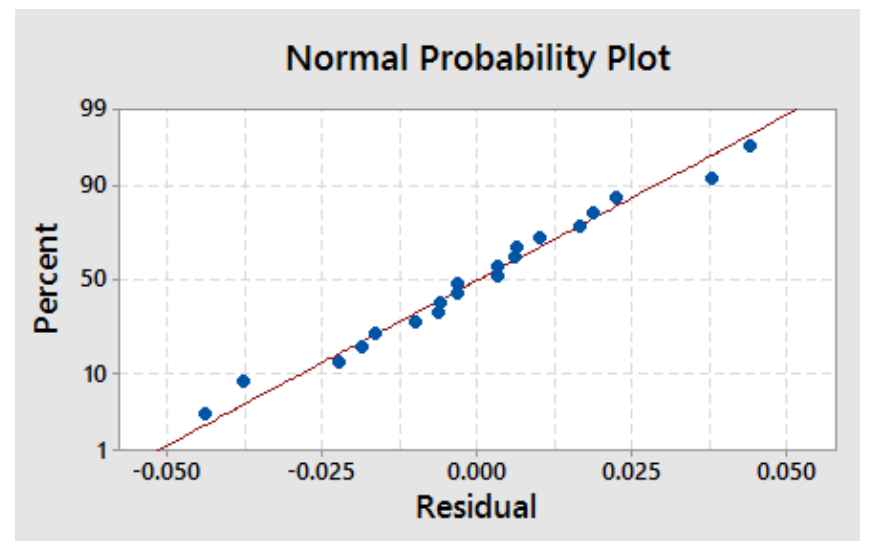

Figure 4: The normal probability plot of the residuals for penetration

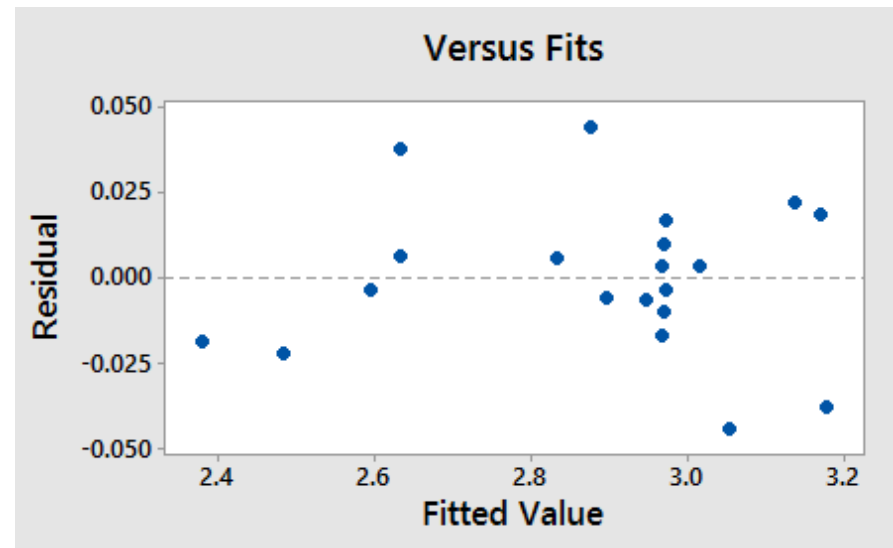

Figure 5: Versus fits 


\section{Asia Pacific Journals}

Figure 4 and 5 represent the standardized residuals and random distribution of fitted values. The residual distribution of the regression equation was normal, and an independent pattern was observed [14]. This result demonstrates the adequacy of the quadratic model for evaluating the tensile behavior of FS-welded specimens. The obtained points were close to the straight line. The data follows a normal distribution except for four outliers.

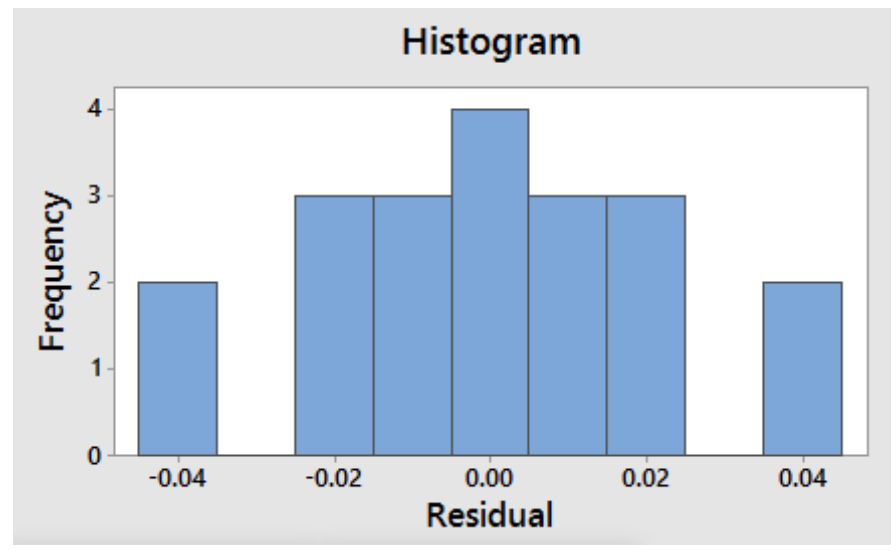

Figure 6: Histogram

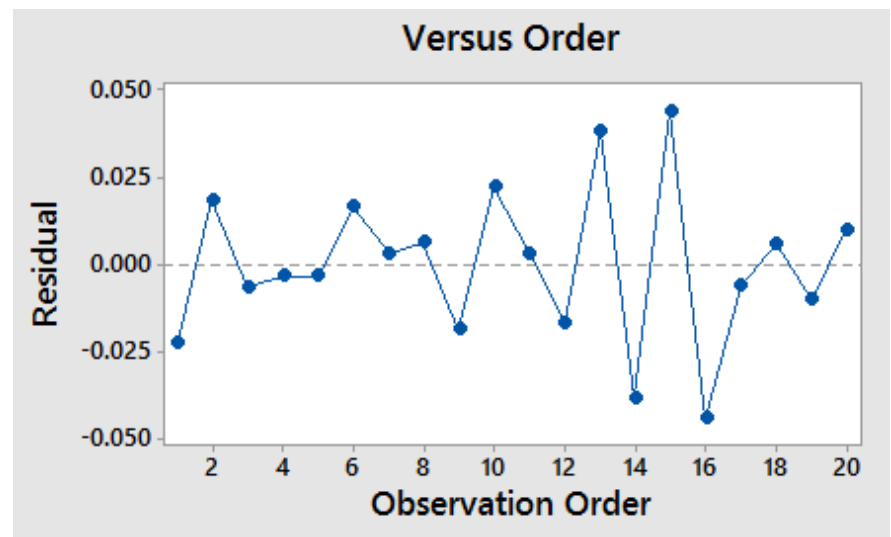

Figure 7: Versus order

Figure 6 and 7 represent the histogram and observation order of the residual plot. The numerous residual points were normally distributed on each side and many lay between-0.025 and 0.025 . This result confirms the error was unevenly distributed. The residual plot shows an unrecognizable pattern and indicates the residuals are randomly scattered around zero. This finding implies that the reduced quadratic model has high adequacy for the error variables.

\subsection{Optimizing Parameters}

Contour plots show distinctive circular shape indicative of possible independence of factors with response. A contour plot is produced to visually display the region of optimal factor settings. For second order response surfaces, such a plot can be more complex than the simple series of parallel lines that can occur with first order models. Once the stationary point is found, it is usually necessary to characterize the response surface in the immediate vicinity of the point by identifying whether the stationary point found is a maximum response or minimum response or a saddle point. To classify this, the most straightforward way is to examine through a contour plot. Contour plots play a very important role in the study of the response surface. By generating contour plots using software for response surface analysis, the optimum is located with reasonable accuracy by characterizing the shape of the surface. If a contour patterning of circular shaped contours occurs, it tends to suggest independence of factor effects while elliptical contours as may indicate factor interactions [15].

Response surfaces have been developed for both the models, taking two parameters in the middle level and two parameters in the $\mathrm{X}$ and $\mathrm{Y}$ axis and response in $\mathrm{Z}$ axis. The response surfaces clearly reveal the optimal response point. RSM is

used to find the optimal set of process parameters that produce a maximum or minimum value of the response [16]. In the present investigation the process parameters corresponding to the maximum weld penetration are considered as optimum (analyzing the contour graphs and by solving Eq. (4)). Hence, when these optimized process parameters are used, then it will be possible to attain the maximum depth of weld penetration.

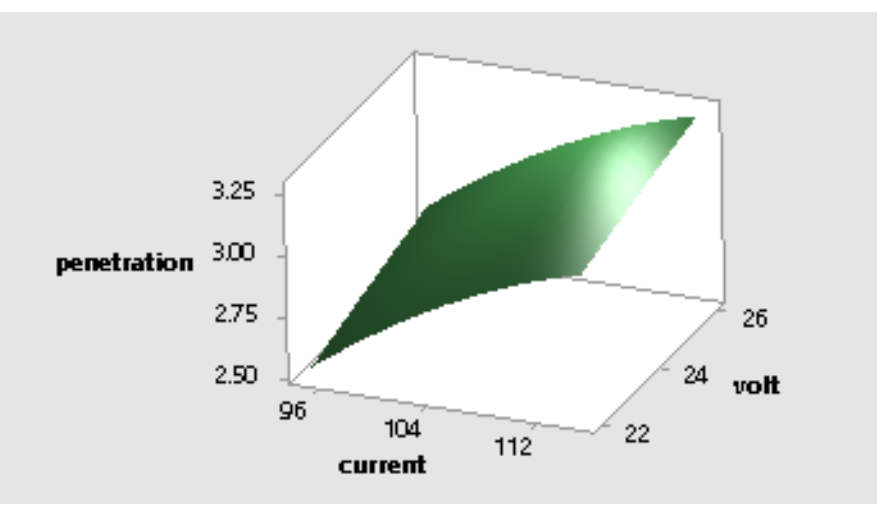

Figure 8: Current, Volt vs. Penetration

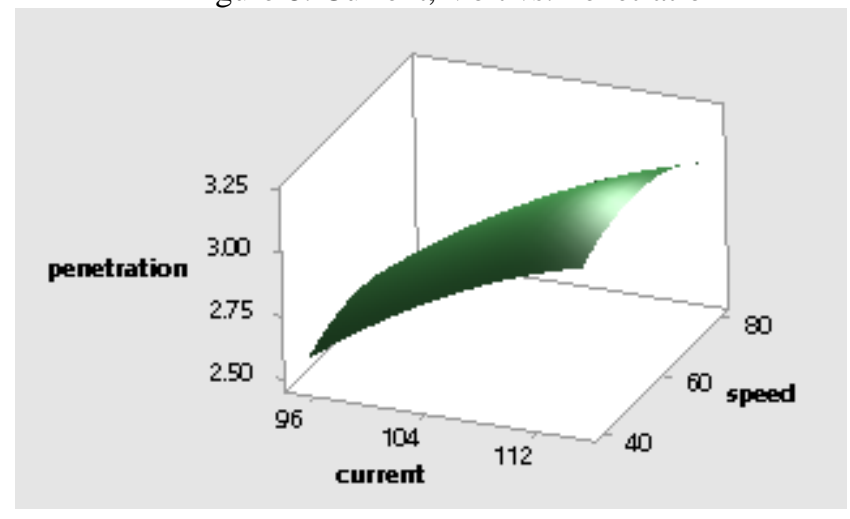

Figure 9: Current, speed vs. Penetration 
Asia Pacific Journals

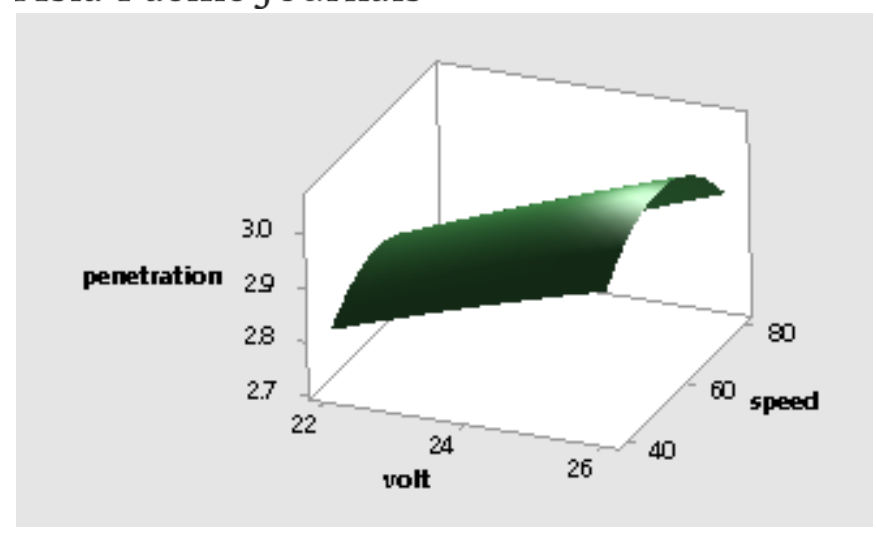

Figure 10: Volt, speed vs. Penetration

Figure 8, 9 and 10 presents three dimensional response surface plots for the response penetration obtained from the regression model. The optimum tensile strength is exhibited by the apex of the response surface.

Predicted optimum weld penetration obtained from the response surface and contour plots by using arc voltage of $26 \mathrm{~V}$, welding current of $115 \mathrm{~A}$ and welding speed of 60 $\mathrm{cm} / \mathrm{min}$. To demonstrate the validity of the model, three experiments were conducted at the optimum values of process parameters and average depth of weld penetration of gas metal arc welded mild steel was found to be $3.24 \mathrm{~mm}$, which shows the excellent agreement with the predicted values.

\section{CONCLUSION}

This paper has described the use of design of experiments (DOE) for conducting experiments. A model was developed for predicting penetration of gas metal arc welded mild steel using response surface methodology. From this investigation, the following important conclusions are derived.

1. Welding current is the factor that has greater influence on the penetration, followed by arc voltage and welding speed.

2. A maximum depth of weld penetration of $3.24 \mathrm{~mm}$ is exhibited by the welded joints fabricated with the optimized parameter of $115 \mathrm{~A}$ current, $26 \mathrm{~V}$ volts and 60 $\mathrm{cm} / \mathrm{min}$ welding speed.

\section{References}

1) M. Aghakhani, E. Mehrdad, and E. Hayati "Parametric optimization of gas metal arc welding process by taguchi method on weld dilution", International journal of modeling and optimization, vol. 1, no. 3, august 2011

2) M. A. Wahab and M. J. Painter "Numerical models of gas metal arc welds using experimentally determined weld pool shapes as the representation of the welding heat source," International journal of pressure vessel \& piping 73 (1997) 153-159

3) B. Das, B. Debbarma, R. N. Rai and S. C. Saha "Influence of process parameters on depth of penetration of welded joint in mig welding process," International journal of research in engineering and technology 02 issue: 10-oct-2013 issn: 2321-7308

4) GUNARAJ V, MURUGAN N. Application of response surface methodology for predicting weld bead quality in submerged arc welding of pipes [J]. Journal of Material Processing Technology,1999, 88: $266-275$.
5) Manonmani K, Murugan N, Buvanasekaran G. Effect of process parameters on the weld bead geometry of laser beam welded stainless steel sheets [J]. Int J Joining Mater, 2005, 17(4): 103-109.

6) Balasubramanian M, Jayabalan V, Balasubramanian V. Developing mathematical models to predict tensile properties of pulsed current gas tungsten arc welded Ti-6Al-4V alloy [J]. Materials and Design, 2008, 29(1): 92-97.

7) Palani P K, Murugan N. Optimization of weld bead geometry for stainless steel claddings deposited by FCAW [J]. Journal of Materials Processing Technology, 2007, 190: 291-299.

8) DUTTA P, PRATIHAR D K. Modeling of TIG welding process using conventional regression analysis and neural network-based approaches [J]. Journal of Materials Processing Technology, 2007,

184: $56-68$.

9) ATES H. Prediction of gas metal arc welding parameters based on artificial neural networks [J]. Materials and Design, 2007, 28: 2015-2023.

10) OKUYUCU H, KURT A, ARCAKLIOGLU E. Artificial neural network application to the friction stir welding of aluminum plates [J]. Materials and Design, 2007, 28(1): 78-84.

11) COCHRAN, COX G M. Experimental design [M]. New Delhi: Asia Publishing House, 1962.

12) Balasubramanian $M$, Jayabalan V, Balasubramanian V. A mathematical model to predict impact toughness of pulsed current gas tungsten arc welded titanium alloy [J]. Journal of Advanced Manufacturing Technology, 2008, 35(9/10): 852-858.

13) Kumar S, Kumar P, Shan H S. Effect of evaporative casting process parameters on the surface roughness of Al-7\% Si alloy castings [J]. Material Processing Technology, 2007, 182: 615-623.

14) S. Hwang, Y. Lee, K. Yang, Maximization of acetic acid production in partial acidogenesis of swine wastewater. Bio. Technol. Bio. Eng. 75, 521-529 (2001)

15) MONTGOMERY D C. Design and analysis of experiments New York: John Wiley, 2001.

16) Hou T H, Su C H, Liu W L. Parameter's optimization of a nano-particle wet milling process using the Taguchi method, response surface method and genetic algorithm [J]. Powder Technology, 2007, 173: 153-162. 